\title{
Association of lead and cadmium exposure with frailty in US older adults
}

Esther García-Esquinas (MD, PhD) ${ }^{\mathbf{a}, \mathbf{b}}$, Ana Navas-Acien $(\mathrm{MD}, \mathrm{PhD})^{\mathbf{b}, \mathbf{c}, \mathbf{d}, \text {, Beatriz }}$ Pérez-Gómez ${ }^{\mathbf{e}}(\mathrm{MD}, \mathrm{PhD}){ }^{\mathrm{e}}$, Fernando Rodríguez Artalejo (MD, PhD) a .

${ }^{a}$ Department of Preventive Medicine and Public Health. School of Medicine.

Universidad Autónoma de Madrid/ IdiPAZ, and CIBER of Epidemiology and Public Health (CIBERESP), Madrid, Spain

${ }^{\mathrm{b}}$ Department of Environmental Health Sciences, Johns Hopkins University Bloomberg School of Public Health, Baltimore, Maryland

${ }^{c}$ Department of Epidemiology, Johns Hopkins University Bloomberg School of Public Health, Baltimore, Maryland

${ }^{\mathrm{d}}$ Welch Center for Prevention, Epidemiology, and Clinical Research, Johns Hopkins University Bloomberg School of Public Health, Baltimore, Maryland

${ }^{\mathrm{e}}$ Environmental Epidemiology and Cancer Unit, National Center for Epidemiology, Carlos III Institute of Health, and CIBER of Epidemiology and Public Health (CIBERESP), Madrid, Spain

Word Count: 6068

\section{Corresponding author/Requests for reprints:}

Esther García García-Esquinas, MD, PhD

Department of Preventive Medicine and Public Health, School of Medicine.

Universidad Autónoma de Madrid.

Calle del Arzobispo Morcillo 4.

28029 Madrid, Spain

Phone: (+34) 91-497-27-61 
E-mail: esthergge@gmail.com

Running title: Association of lead and cadmium with frailty

\section{Acknowledgments:}

Grant information: This work has been supported by grants from the Instituto de Salud Carlos III, Ministry of Health of Spain (PI12/1166) and from the European Commission (FRAILOMIC Initiative FP7-HEALTH-2012-Proposal No: 305483-2).

Conflicts of interest: The authors declare they have no actual or potential competing financial interests.

Contributions: EGE conceived the study, performed the statistical analyses and drafted the manuscript. FRA, ANA and BPG drafted and reviewed the manuscript for important intellectual content. EGE and FRA had primary responsibility for the final content. 


\begin{abstract}
Background: Environmental lead and cadmium exposure is associated with higher risk of several age-related chronic diseases, including cardiovascular disease, chronic kidney disease and osteoporosis. These diseases may lead to frailty, a geriatric syndrome characterized by diminished physiologic reserve in multiple systems with decreased ability to cope with acute stressors. However, no previous study has evaluated the association between lead or cadmium exposure and frailty.
\end{abstract}

Methods: Cross-sectional study among individuals aged $\geq 60$ years who participated in the third U.S. National Health and Nutrition Examination Survey and had either blood lead $(\mathrm{N}=5,272)$ or urine cadmium $(\mathrm{N}=4,887)$ determinations. Frailty was ascertained with a slight modification of the Fried criteria, so that individuals meeting $\geq 3$ of 5 predefined criteria (exhaustion, low body weight, low physical activity, weakness and slow walking speed), were considered as frail. The association between lead and cadmium with frailty was evaluated using logistic regression with adjustment for relevant confounders.

Results: Median (intertertile range) concentrations of blood lead and urine cadmium were $3.9 \mu \mathrm{g} / \mathrm{dl}(2.9-4.9)$ and $0.62 \mu \mathrm{g} / \mathrm{l}(0.41-0.91)$, respectively. The prevalence of frailty was $7.1 \%$. The adjusted odds ratios (95\% confidence interval) of frailty comparing the second and third to the lowest tertile of blood lead were, respectively, $1.40(0.96-2.04)$ and 1.75 (1.33-2.31). Lead concentrations were also associated with the frequency of exhaustion, weakness and slowness. The corresponding odds ratios (95\% confidence interval) for cadmium were, respectively, $0.97(0.68-1.39)$ and 1.55 (1.03-2.32), but this association did not hold after excluding participants with reduced glomerular filtration rate: $0.70(0.43-1.14)$ and $1.09(0.56-2.11)$, respectively. 
Conclusions: In the US older adult population, blood lead but not urine cadmium concentrations showed a direct dose-response relationship with frailty. These findings support that lead exposure increases frailty in older adults.

Key words: Lead, cadmium, frailty, muscle strength 


\section{INTRODUCTION}

Frailty is a geriatric syndrome characterized by a decreased ability to cope with acute stressors resulting from aging-related decline in reserve and function of multiple physiologic systems, including the cardiovascular, metabolic, immune, endocrine, or nervous systems (Clegg et al. 2013). The progressive accumulation of deficits in these systems increases the risk of disease onset and leads to a cycle of events (i.e. undernutrition, sarcopenia, diminished strength or exercise intolerance) that perpetuate frailty. With the addition of new stressors, the cycle of frailty can easily progress to disability (Vermeulen et al. 2011), institutionalization (Fried et al. 2001) and death (Graham et al. 2009; Song et al. 2010). Given the serious consequences of frailty and its high frequency, which reaches $10 \%$ of individuals over 60 years and $25 \%$ of those over 80 (Clegg et al. 2013), extensive research is being conducted to determine why some older adults become frail, and to identify preventable risk factors and mechanistic pathways. Despite this effort, few studies have evaluated the role of environmental contaminants on the risk of frailty, and most of them have focused on the effects of air pollution (Eckel et al. 2012; Myers et al. 2013).

The Environmental Protection Agency (EPA) has identified common environmental exposures that may especially harm the health of older adults, including metals, pesticides, water contaminants or air particles. For some contaminants (i.e. organic pollutants, certain metals) this increased risk may be related to bioaccumulation over the lifetime. Higher vulnerability in older adults may also partly result from age-related alterations in cellular function which impair the capability to maintain physiologic homeostasis (Geller and Zenick 2005). Additionally, aging is associated with major 
changes in body composition that could influence the absorption and distribution of environmental chemicals in human tissues (Nordberg et al. 2007).

Lead and cadmium are two toxic metals widely distributed in the environment that accumulate in the human body, resulting in chronic endogenous exposure tissues (Nordberg et al. 2007). Increasing evidence supports the contribution of environmental lead and cadmium to the development of several age-related chronic diseases, including cardiovascular disease (Navas-Acien et al. 2007; Tellez-Plaza et al. 2013b), chronic kidney disease (Navas-Acien et al. 2009), and osteoporosis (Engstrom et al. 2011;Gallagher et al. 2008; Khalil et al. 2008). Despite this evidence, and the established connection between these diseases and the frailty syndrome (Heuberger 2011), no previous studies have examined the association between lead or cadmium exposure and frailty. To evaluate this question, we used data from the third US National Health and Nutrition Examination Survey (NHANES III). We hypothesized that increasing concentrations of blood lead or urine cadmium are associated with increasing frequency of frailty in older adults.

\section{METHODS}

\section{Study participants}

NHANES III was a multistage, stratified, clustered probability survey of the US civilian non-institutionalized population, conducted between 1988 and 1994 by the National Center for Health Statistics. The survey consisted of a household interview and a standardized physical examination performed in a mobile center. Our analysis was 
initially limited to adults $\geq 60$ years of age who had completed the physical examination $(\mathrm{N}=5,724)$. For our study, we further restricted the sample to participants who had either blood lead or urine cadmium determinations available $(\mathrm{N}=5,579)$. The study was approved by the NHANES Institutional Review Board (IRB), and written informed consent was obtained from all subjects.

\section{Study variables}

\section{Lead and Cadmium}

Blood and spot urine samples were collected during the physical examination. All collection and storage materials used for metal analysis were prescreened for background contamination levels. Blood lead concentrations were measured by graphite furnace atomic absorption spectrophotometry. The limit of detection (LOD) for blood lead was $1 \mu \mathrm{g} / \mathrm{dl}$ and the interassay coefficients of variation ranged from 2.78 to $8.11 \%$. For $2.8 \%$ of the participants with blood lead concentrations under the LOD, these were replaced by the LOD divided by the squared root of 2 .

Urine cadmium was measured by Zeeman effect graphite furnace atomic absorption. The LOD for cadmium was $0.03 \mu \mathrm{g} / \mathrm{dl}$ and the interassay coefficients of variation ranged from 2.83 to $13.57 \%$. Cadmium was undetectable for $2.5 \%$ of the participants and the levels replaced by the LOD divided by the square root of 2 . To account for urine dilution, cadmium levels were either adjusted or divided by urine creatinine $(\mu \mathrm{g} / \mathrm{g})$. Additional details regarding laboratory procedures have been described in detail (Gunter et al. 1996). 


\section{Frailty}

Assessment of frailty was performed using a modification of the definition developed by Fried and colleagues (Fried et al. 2001) in the Cardiovascular Health Study (CHS). Individuals meeting $\geq 3$ of the following criteria were considered as frail: 1) Exhaustion, defined as any of these responses "some difficulty", "much difficulty" or "unable to do it" to the question "How much difficulty do you have walking from one room to the other on the same level?"; 2) Low body weight, characterized by a body mass index (BMI) $\leq 18 \mathrm{~kg} / \mathrm{m}^{2}$; 3) Low physical activity, considered present if the individual answered "less active" to the following question: "When compared to most men/women of your age, would you say that you are more active, less active or about the same?"; 4) Weakness, defined as any of these responses "some difficulty", "much difficulty" or "unable to do it" to the question "How much difficulty you have lifting or carrying something as heavy as 10 pounds? “; 5) Slow walking speed, defined as the worse quintile in the eight-foot walking speed test, adjusted for sex and height (Guralnik et al. 1994). The main modifications with respect to the CHS definition of frailty were that the nutrition criterion was based on low BMI rather than on weight loss in the preceding months, and that weakness was self-reported rather than based on the direct assessment of grip strength; similar modifications are common in the frailty literature, and usually result from the information available in each dataset.

\section{Other variables}


We collected data from a number of variables (gender, age, education, race/ethnicity, tobacco smoking, number of smokers at home and number of drug treatments used) that may act as potential confounders because they have shown to be independently associated with the outcome (Fried et al. 2001; Mello Ade C et al. 2014) and with the exposure (Nordberg et al. 2007). Additionally, participants were asked about medical conditions that could be acting as mediators of the studied association (i.e previous history of cardiovascular disease (congestive heart failure, coronary heart disease, angina or stroke), hypertension, diabetes, osteoarticular disease (osteoporosis, rheumatoid arthritis and osteoarthritis), respiratory disease (asthma, chronic bronchitis or emphysema) and cancer).

Weight and height were measured in standardized conditions, and BMI was calculated as weight in $\mathrm{kg}$ divided by squared height in $\mathrm{m}$. During the medical examination, blood pressure was measured three times with the participant seated for 5 minutes and using an appropriate sized cuff. Hypertension was defined as self-reported physician diagnosis of high blood pressure or a mean systolic/diastolic blood pressure $\geq 140 / 90 \mathrm{~mm} \mathrm{Hg}$. Serum creatinine was measured using the modified kinetic Jaffe reaction, with a coefficient of variation that ranged between 0.2 and $1.4 \%$. Chronic kidney disease was defined as a glomerular filtration rate (GFR) $<60 \mathrm{~mL} / \mathrm{min}$ per $1.73 \mathrm{~m}^{2}$, estimated using the CKD-EPI equation (Levey et al. 2009). Serum cotinine was measured using high performance liquid chromotography/atmospheric pressure chemical ionization tandem mass spectrometry. The LOD for serum cotinine using this method was $0.05 \mathrm{ng} / \mathrm{ml}$ and values under the LOD were replaced by the square root of 2 .

\section{Statistical analyses}


From the initial sample size of 5,579 individuals, we excluded 85 with missing values in $\geq 3$ frailty domains and 86 with missing data on potential confounders ( 44 on education, 5 on BMI, 5 on the number of smokers at home, 28 on self-reported chronic conditions, and 4 on number of drug treatments). From the remaining 5,408 participants, for lead analyses we excluded 136 individuals who lacked data on blood lead and for cadmium analyses we excluded 521 subjects without data on urine cadmium. This led to a final analytical sample of 5,272 (94.5\%) and 4,887 (87.6\%) adults for blood lead and urine cadmium analyses, respectively. Study participants were similar in sociodemographic and frailty risk factors to the overall study population (data not shown).

The association of blood lead and urine cadmium concentrations with frailty or its components was evaluated with odds ratios (OR) and their 95\% confidence interval (CI) obtained from logistic regression. Three logistic models were built. Model 1 was unadjusted. Model 2 was adjusted for sex and age, and model 3 was additionally adjusted for educational level, ethnicity, BMI, tobacco smoking (never/former/current), number of smokers at home, cardiovascular disease, hypertension, diabetes, osteoarticular disease, respiratory disease, cancer and number of drug treatments. In the analyses, lead and cadmium were classified into tertiles, with the lowest tertile being the exposure reference. We also modeled $\ln$-transformed lead and $\ln$-transformed cadmium as continuous variables, and expressed the results per intertertile range increase in lnmetal concentrations. In addition, we modeled lead and cadmium as restricted cubic splines with knots at the $10^{\text {th }}, 50^{\text {th }}$ and $90^{\text {th }}$ percentiles.

We conducted a number of sensitivity analyses to assess the robustness of the results. First, to account for current exposure to tobacco smoke, including secondhand smoke, that is a source of lead and cadmium (Apostolou et al. 2012; Tellez-Plaza et al. 2012), 
we repeated the analyses with further adjustment for serum cotinine concentrations, among individuals with this information available $(\mathrm{N}=4,796$ for lead; $\mathrm{N}=4,596$ for cadmium). Second, to account for urine dilution, cadmium concentrations were divided by urine creatinine instead of adjusting for this variable. Third, we also performed the analyses without accounting for urine dilution. Fourth to rule out the potential role of variations in cadmium excretion related to kidney function, the analyses were also run only among individuals with GFR in the normal range $\left(>60 \mathrm{~mL} / \mathrm{min} / 1.73 . \mathrm{m}^{2}\right)$. Fifth, we adjusted lead models for cadmium concentrations and cadmium models for lead concentrations, and we evaluated for potential interactions among both metals. Finally, in exploratory analyses, we evaluated the consistency of the findings across participant subgroups, we evaluated for potential interactions by sex, age, education, ethnicity, BMI, tobacco smoke, number of smokers at home and serum cotinine concentrations by adding interaction terms and then generating stratum-specific estimates.

Statistical analyses were performed with the STATA v.13.0 software (Stata Corp, College Station, TX) by using the survey procedures to account for the complex sampling design in NHANES III

\section{RESULTS}

The median (intertertile range) concentrations of blood lead and urine cadmium were $3.9 \mu \mathrm{g} / \mathrm{dl}(2.9-4.9)$ and $0.62 \mu \mathrm{g} / \mathrm{l}(0.41-0.91)$, respectively. Blood lead concentrations were higher among men, non-Hispanic black, participants with lower education or lower BMI, ever smokers, those living with at least one smoker, as well as in those with decreased GFR and chronic respiratory disease (table 1). Urine cadmium concentrations were higher in younger participants, non-hispanic blacks, current smokers, individuals living with smokers, with lower education, lower BMI, decreased GFR, and in those 
diagnosed with cardiovascular disease or chronic respiratory disease (table 1).

Correlation among blood lead and urine cadmium was low $(\mathrm{r}=0.20)$,

The prevalence of frailty was $7.1 \%$. Frailty was more common among women, participants $\geq 74$ years of age, non-Hispanic black and Mexican-American participants, and participants with lower education. After multivariate adjustment, the OR (95\%CI) of frailty comparing the second and third tertiles of blood lead to the lowest tertile were, respectively, $1.40(0.96-2.04)$ and 1.75 (1.33-2.31); (model 3, table 2). The corresponding results for cadmium were $0.97(0.68-1.39)$ and $1.55(1.03-2.32)$. The odds ratio for frailty associated with an intertertile range increase in blood lead was 1.20 (95\% CI 1.08-1.33), and the corresponding odds ratio for an intertertile increase in urine cadmium was 1.30 (95\% CI 0.94-1.81).. Further adjustment for serum cotinine (for both lead and cadmium) or dividing cadmium by creatinine instead of adjusting for logtransformed urine creatinine provided similar results (models 4 and 5, table 2). When restricting the analyses to individuals with normal GFR, the results were similar for lead but no association was observed between cadmium and frailty (model 7, table 2); in this subgroup of participants the OR $(95 \% \mathrm{CI})$ of frailty for cadmium tertiles 2 and 3 compared to the lowest tertile were $0.70(0.43-1.14)$ and $1.09(0.56-2.11)$ (model 7 , table 2).

In spline regression models (figure 1), the dose-response relationship was progressive over the range of blood lead concentrations ( $\mathrm{p}$ value for the nonlinear component $=0.46$ ), while the association with cadmium showed a nonlinear pattern ( $\mathrm{p}$ values for the nonlinear component $<0.01$ in model B among the total study sample, and 0.03 in model $\mathrm{C}$ among individuals with normal GFR). 
The most prevalent frailty components were weakness and slowness, while low BMI was the least frequent. Figure 2 presents the results for the association between the studied metals and the five frailty criteria. Analyses for cadmium are based on participants with normal estimated GFR. Individuals in the highest tertile of blood lead concentrations showed an increased frequency of exhaustion (OR 1.72; 95\%CI 1.252.37), weakness (OR 1.30; 95\%CI 1.00-1.73) and slowness (OR 1.29; 95\%CI 1.001.58). Urine cadmium levels were only associated with greater frequency of low BMI (OR comparing the highest to lowest tertile: 2.56; 95\%CI: 1.21-7.74).

In interaction analyses, results for lead were consistent across all participant's subgroups evaluated, including smoking status and cotinine concentrations (figure 3 ). Similarly, no effect modification by morbidity status was observed. We were particularly interested in evaluating potential effect modification by osteoporosis, as lead is stored in bones. The association of lead with frailty was somewhat stronger among women with osteoporosis: the OR $(95 \% \mathrm{CI})$ for frailty for the second and third tertiles compared to the lowest one were: $1.86(1.06-3.28)$ and $4.23(1.64-10.88)$ in women with osteoporosis and $1.40(0.87-2.27)$ and $2.12(1.00-7.41)$ in women without osteoporosis ( $\mathrm{p}$ interaction: 0.23 ). For cadmium, there was effect modification by tobacco smoking $(\mathrm{p}=0.02)$, with results suggesting that a positive association between this metal and frailty may be limited to current smokers (OR of frailty for an intertertile increase in urine cadmium among smokers: 2.85 ; 95\%CI: $1.00-8.14$ in individuals with normal GFR). No changes in the results were observed when lead models were adjusted for cadmium or when cadmium levels were adjusted for lead. 


\section{DISCUSSION}

In the US older adult population, blood lead concentrations showed a positive doseresponse relationship with frailty. For cadmium, no overall association with frailty was found but there was was some evidence of a putative adverse relationship only at high exposure levels.

Lead and cadmium may influence the risk of frailty through several mechanisms. First, there is experimental evidence that these metals increase oxidative stress and inflammation (Jomova and Valko 2011), which, in turn, play an important role in the development of frailty. Specifically, frail individuals have elevated concentrations of biomarkers of oxidative-stress (malondialde-Hyde, 8-oxo-7,8-dihydro-2'deoxyguanosine (Ingles et al. 2014;Wu et al. 2009)) and inflammation (IL-6, C-reactive protein, fibrinogen (Gale et al. 2013;Li et al. 2011)). Second, exposure to lead and cadmium has been related to a higher risk of several pathologic conditions that are also linked to frailty. Environmental exposure to lead in the elderly has been associated with cognitive decline (Bandeen-Roche et al. 2009; Grashow et al. 2013;Nordberg et al. 2000; Power et al. 2014; Shih et al. 2006; van Wijngaarden et al. 2011), impaired motor skills (Grashow et al. 2013), increased blood pressure (Perlstein et al. 2007), ischemic heart disease (Jain et al. 2007), decreased renal function (Tsaih et al. 2004), falls and fractures in women (Khalil et al. 2008), hearing loss (Park et al. 2010) and vision problems (Schaumberg et al. 2004;Wu et al. 2014). Cadmium, for which fewer studies have been conducted in the elderly, has also been associated with an increased risk of

atherosclerotic plaques (Fagerberg et al. 2012), peripheral artery disease (Tellez-Plaza et al. 2013a), osteoporosis (Engstrom et al. 2011;Gallagher et al. 2008) and macular 
degeneration (Shiue 2013; Wu et al. 2014). In addition, a decrease in muscle mass and muscle strength, which are components of frailty (Cesari et al. 2006), might also contribute to the observed associations. Thus, to explore this possibility in the study sample, we estimated muscle mass with the formula proposed by Janssen et al. (2002) and observed that a $1 \%$ increase in blood lead concentrations was associated with a decrease of $0.72 \%(95 \% \mathrm{CI}-1.27 ;-0.16)$ in muscle mass, while a $1 \%$ increase in urine cadmium was linked to a reduction of $0.65 \%(95 \% \mathrm{CI}-1.24 ;-0.07)$. These findings suggest that lead and cadmium could increase the risk of frailty through alterations in the musculoskeletal system.

No previous study has evaluated the association between heavy metals and frailty. However, two reports from the continuous NHANES (1999-2004) have explored the link of blood lead (Ji et al. 2013) and urine cadmium (Lang et al. 2009) with mobility outcomes among the elderly population. The first of these studies (Ji et al. 2013), reported that walking speed decreased with increasing blood lead concentrations in women, but not in men. Contrary to these results, we found an association between blood lead concentrations and low gait speed in both men and women (data not shown). The second study (Lang et al. 2009) found a positive crude association between urine cadmium and "self-reported problems with walking a quarter of a mile", but this association was not maintained after adjustment for urine creatinine. Lastly, in the VA Normative Aging Study, bone lead concentration was associated with reduced fine motor performance over a 30-month follow-up (Grashow et al. 2013).

More than $90 \%$ of lead is accumulated in the bones, from where it can be released to blood. Blood lead, the most commonly used biomarker of lead exposure, has a 
relatively short half-life, and reflects both recent exogenous exposure as well as chronic exposure from mobilization of bone stores tissues (Skerfving and Bergdahl 2007). Under conditions of accelerated bone turnover and mineral loss (i.e. postmenopausal osteoporosis; ageing-related loss of bone mass), lead stored in bones throughout life is released into circulation, increasing the correlation between blood lead concentrations and chronic exposure, as measured by patella lead levels (Tsaih et al. 2001). In this sense, it is interest to note that the magnitude of the observed effects in our population tended to be higher among older individuals and among women who had been previously diagnosed with osteoporosis, although effect modification was not statistically significant.

Cadmium is a cumulative element with a biological half-life of more than 10 years, and urine cadmium is a good biomarker of long-term exposure (Jarup and Akesson 2009). Recent studies have suggested that cadmium bioaccumulation may only occur until age 60 , when urine cadmium concentrations would level off or even decrease due to physiological variations in renal function (Chaumont et al. 2013). It is difficult to anticipate how these variations with age could affect the interpretation of our results. In any case, given that the association between cadmium and frailty disappeared after excluding participants with reduced GFR, it is possible that the observed results in the total study sample reflected the underlying association between kidney disease and frailty. Accordingly, Wilhelm-Leen and colleagues (2009) recently reported a positive association between chronic kidney disease and frailty using data from the III NHANES. Thus, future prospective studies should exclude individuals with reduced kidney function at study entry. Special attention should be paid to current smokers, in 
whom the observed association may reflect the combined toxic effect of cadmium and other tobacco chemicals.

Strengths of this study included the large sample, which was representative of the US general population aged $\geq 60$ years, the high quality laboratory methods, as well as the number of potential confounders evaluated. However, this study also had several limitations. First, NHANES III was a cross-sectional study so causal relationships cannot be established. However, since blood lead and urine cadmium reflect, at least partially, chronic exposure to these metals, and given that the life expectancy of frail individuals is limited, it is reasonable to assume that the exposures preceded the development of frailty. Second, the study sample did not include institutionalized individuals, so the study results may not apply to this population group. Third, we used a single spot urine sample to measure cadmium concentrations. However, different strategies to account for urine dilution yielded similar results. Moreover, uncertainties in exposure assessment are likely to result in non-differential measurement error and to underestimate the associations. On the other hand, because serum creatinine is released from muscle mass and muscle mass is inversely correlated with frailty, creatinine correction could also be biasing cadmium results. Finally, we used low BMI as an indicator of frailty because the NHANES III lacked information on weight loss. However, analyses excluding the weight loss criteria from the definition of frailty and considering as frail those with $>3$ of the 4 remaining criteria, showed the same results.

\section{CONCLUSION}


Exposure to lead is positively associated with frailty. Although it is difficult to determine the impact of age-related variations in renal function on cadmium excretion in the elderly, the results of this study do not support an overall association between cadmium exposure and frailty. Future prospective studies should confirm the observed results. 


\section{REFERENCES}

Apostolou A, Garcia-Esquinas E, Fadrowski JJ, McLain P, Weaver VM, Navas-Acien A. 2012. Secondhand tobacco smoke: a source of lead exposure in US children and adolescents. Am J Public Health 102: 714-722. doi: 10.2105/AJPH.2011.300161.

Bandeen-Roche K, Glass TA, Bolla KI, Todd AC, Schwartz BS. 2009. Cumulative lead dose and cognitive function in older adults. Epidemiology 20: 831-839. doi: 10.1097/EDE.0b013e3181b5f100.

Cesari M, Leeuwenburgh C, Lauretani F, Onder G, Bandinelli S, Maraldi C, et al. 2006. Frailty syndrome and skeletal muscle: results from the Invecchiare in Chianti study. Am J Clin Nutr 83: 1142-1148.

Chaumont A, Voisin C, Deumer G, Haufroid V, Annesi-Maesano I, Roels H, et al. 2013. Associations of urinary cadmium with age and urinary proteins: further evidence of physiological variations unrelated to metal accumulation and toxicity. Environ Health Perspect 121: 1047-1053. doi: 10.1289/ehp.1306607.

Clegg A, Young J, Iliffe S, Rikkert MO, Rockwood K. 2013. Frailty in elderly people. Lancet 381: 752-762. doi: 10.1016/S0140-6736(12)62167-9.

Eckel SP, Louis TA, Chaves PH, Fried LP, Margolis AH. 2012. Modification of the association between ambient air pollution and lung function by frailty status among older adults in the Cardiovascular Health Study. Am J Epidemiol 176: 214-223. doi: 10.1093/aje/kws001. 
Engstrom A, Michaelsson K, Suwazono Y, Wolk A, Vahter M, Akesson A. 2011. Long-term cadmium exposure and the association with bone mineral density and fractures in a population-based study among women. J Bone Miner Res 26: 486-495. doi: 10.1002/jbmr.224.

EPA (Environmental Protection Agency). 2014. The aging initiative. Available: http://www.epa.gov/aging. [accessed 16 September 2014].

Fagerberg B, Bergstrom G, Boren J, Barregard L. 2012. Cadmium exposure is accompanied by increased prevalence and future growth of atherosclerotic plaques in 64-year-old women. J Intern Med 272: 601-610. doi: 10.1111/j.13652796.2012.02578.x.

Fried LP, Tangen CM, Walston J, Newman AB, Hirsch C, Gottdiener J, et al. 2001. Frailty in older adults: evidence for a phenotype. J Gerontol A Biol Sci Med Sci 56: M146-M156.

Gale CR, Baylis D, Cooper C, Sayer AA. 2013. Inflammatory markers and incident frailty in men and women: the English Longitudinal Study of Ageing. Age (Dordr ) 35: 2493-2501. doi: 10.1007/s11357-013-9528-9.

Gallagher CM, Kovach JS, Meliker JR. 2008. Urinary cadmium and osteoporosis in U.S. Women >or= 50 years of age: NHANES 1988-1994 and 1999-2004. Environ Health Perspect 116: 1338-1343. doi: 10.1289/ehp.11452.

Geller AM, Zenick H. 2005. Aging and the environment: a research framework. Environ Health Perspect 113: 1257-1262. 
Graham JE, Snih SA, Berges IM, Ray LA, Markides KS, Ottenbacher KJ. 2009. Frailty and 10-year mortality in community-living Mexican American older adults.

Gerontology 55: 644-651. doi: 10.1159/000235653.

Grashow R, Spiro A, Taylor KM, Newton K, Shrairman R, Landau A, et al. 2013.

Cumulative lead exposure in community-dwelling adults and fine motor function: comparing standard and novel tasks in the VA normative aging study. Neurotoxicology 35: 154-161. doi: 10.1016/j.neuro.2013.01.005.

Gunter EW, Lewis BG, Koncikowski SM. 1996. Laboratory Procedures Used for the Third National Health and Nutrition Examination Survey (NHANES III), 1988-1944. Centers for Disease Control and Prevention (CDC) Available: $\underline{\text { http://www }} \underline{\mathrm{cdc}}$ gov/nchs/data/nhanes/nhanes3/cdrom/nchs/manuals/labman pdf. [accessed 1 September 2014].

Guralnik JM, Simonsick EM, Ferrucci L, Glynn RJ, Berkman LF, Blazer DG, et al. 1994. A short physical performance battery assessing lower extremity function: association with self-reported disability and prediction of mortality and nursing home admission. J Gerontol 49: M85-M94.

Heuberger RA. 2011. The frailty syndrome: a comprehensive review. J Nutr Gerontol Geriatr 30: 315-368. doi: 10.1080/21551197.2011.623931.

Ingles M, Gambini J, Carnicero JA, Garcia-Garcia FJ, Rodriguez-Manas L, OlasoGonzalez G, et al. 2014. Oxidative Stress Is Related to Frailty, Not to Age or Sex, in a Geriatric Population: Lipid and Protein Oxidation as Biomarkers of Frailty. J Am Geriatr Soc. doi: 10.1111/jgs.12876. 
Jain NB, Potula V, Schwartz J, Vokonas PS, Sparrow D, Wright RO, et al. 2007. Lead levels and ischemic heart disease in a prospective study of middle-aged and elderly men: the VA Normative Aging Study. Environ Health Perspect 115: 871-875.

Janssen I, Heymsfield SB, Ross R. 2002. Low relative skeletal muscle mass (sarcopenia) in older persons is associated with functional impairment and physical disability. J Am Geriatr Soc 50: 889-896.

Jarup L, Akesson A. 2009. Current status of cadmium as an environmental health problem. Toxicol Appl Pharmacol 238: 201-208. doi: 10.1016/j.taap.2009.04.020.

Ji JS, Elbaz A, Weisskopf MG. 2013. Association between blood lead and walking speed in the National Health and Nutrition Examination Survey (NHANES 1999-2002). Environ Health Perspect 121: 711-716. doi: 10.1289/ehp.1205918.

Jomova K, Valko M. 2011. Advances in metal-induced oxidative stress and human disease. Toxicology 283: 65-87. doi: 10.1016/j.tox.2011.03.001.

Khalil N, Cauley JA, Wilson JW, Talbott EO, Morrow L, Hochberg MC, et al. 2008. Relationship of blood lead levels to incident nonspine fractures and falls in older women: the study of osteoporotic fractures. J Bone Miner Res 23: 1417-1425. doi: 10.1359/jbmr.080404.

Lang IA, Scarlett A, Guralnik JM, Depledge MH, Melzer D, Galloway TS. 2009. Agerelated impairments of mobility associated with cobalt and other heavy metals: data from NHANES 1999-2004. J Toxicol Environ Health A 72: 402-409. doi: $10.1080 / 15287390802647336$. 
Levey AS, Stevens LA, Schmid CH, Zhang YL, Castro AF, III, Feldman HI, et al. 2009. A new equation to estimate glomerular filtration rate. Ann Intern Med 150: 604612.

Li H, Manwani B, Leng SX. 2011. Frailty, inflammation, and immunity. Aging Dis 2: 466-473.

Mello Ade C, Engstrom EM, Alves LC. 2014. Health-related and socio-demographic factors asociated with frailty in the elderly: a systematic literature review. Cad Saude Publica 30: 1143-68.

Myers V, Broday DM, Steinberg DM, Yuval, Drory Y, Gerber Y. 2013. Exposure to particulate air pollution and long-term incidence of frailty after myocardial infarction. Ann Epidemiol 23: 395-400. doi: 10.1016/j.annepidem.2013.05.001.

Navas-Acien A, Guallar E, Silbergeld EK, Rothenberg SJ. 2007. Lead exposure and cardiovascular disease--a systematic review. Environ Health Perspect 115: 472-482.

Navas-Acien A, Tellez-Plaza M, Guallar E, Muntner P, Silbergeld E, Jaar B, et al. 2009. Blood cadmium and lead and chronic kidney disease in US adults: a joint analysis. Am J Epidemiol 170: 1156-1164. doi: 10.1093/aje/kwp248.

Nordberg GF, Fowler BA, Nordberg M, Friberg L.T. 2007. General considerations and International Perspectives. In: Handbook on the Toxicology of Metals, 3rd edition. Amsterdam: Elsevier, 1-8.

Nordberg M, Winblad B, Fratiglioni L, Basun H. 2000. Lead concentrations in elderly urban people related to blood pressure and mental performance: results from a population-based study. Am J Ind Med 38: 290-294. 
Park SK, Elmarsafawy S, Mukherjee B, Spiro A, III, Vokonas PS, Nie H, et al. 2010. Cumulative lead exposure and age-related hearing loss: the VA Normative Aging Study. Hear Res 269: 48-55. doi: 10.1016/j.heares.2010.07.004.

Perlstein T, Weuve J, Schwartz J, Sparrow D, Wright R, Litonjua A, et al. 2007. Cumulative community-level lead exposure and pulse pressure: the normative aging study. Environ Health Perspect 115: 1696-1700.

Power MC, Korrick S, Tchetgen Tchetgen EJ, Nie LH, Grodstein F, Hu H, et al. 2014. Lead exposure and rate of change in cognitive function in older women. Environ Res 129: 69-75. doi: 10.1016/j.envres.2013.12.010.

Schaumberg DA, Mendes F, Balaram M, Dana MR, Sparrow D, Hu H. 2004.

Accumulated lead exposure and risk of age-related cataract in men. JAMA 292: 27502754.

Shih RA, Glass TA, Bandeen-Roche K, Carlson MC, Bolla KI, Todd AC, et al. 2006. Environmental lead exposure and cognitive function in community-dwelling older adults. Neurology 67: 1556-1562.

Shiue I. 2013. Urinary environmental chemical concentrations and vitamin D are associated with vision, hearing, and balance disorders in the elderly. Environ Int 53: 4146. doi: 10.1016/j.envint.2012.12.006.

Skerfving S, Bergdahl IA. 2007. Lead. In: Handbook on the Toxicology of Metals, 3rd edition. Amsterdam: Elsevier, 599-635. 
Song X, Mitnitski A, Rockwood K. 2010. Prevalence and 10-year outcomes of frailty in older adults in relation to deficit accumulation. J Am Geriatr Soc 58: 681-687. doi: 10.1111/j.1532-5415.2010.02764.x.

Tellez-Plaza M, Guallar E, Fabsitz RR, Howard BV, Umans JG, Francesconi KA, et al. 2013a. Cadmium exposure and incident peripheral arterial disease. Circ Cardiovasc Qual Outcomes 6: 626-633. doi: 10.1161/CIRCOUTCOMES.112.000134.

Tellez-Plaza M, Jones MR, Dominguez-Lucas A, Guallar E, Navas-Acien A. 2013b. Cadmium exposure and clinical cardiovascular disease: a systematic review. Curr Atheroscler Rep 15: 356. doi: 10.1007/s11883-013-0356-2.

Tellez-Plaza M, Navas-Acien A, Caldwell KL, Menke A, Muntner P, Guallar E. 2012. Reduction in cadmium exposure in the United States population, 1988-2008: the contribution of declining smoking rates. Environ Health Perspect 120: 204-209.

Tsaih SW, Korrick S, Schwartz J, Amarasiriwardena C, Aro A, Sparrow D, et al. 2004. Lead, diabetes, hypertension, and renal function: the normative aging study. Environ Health Perspect 112: 1178-1182. doi: 10.1289/ehp.1104020.

Tsaih SW, Korrick S, Schwartz J, Lee ML, Amarasiriwardena C, Aro A, et al. 2001. Influence of bone resorption on the mobilization of lead from bone among middle-aged and elderly men: the Normative Aging Study. Environ Health Perspect 109: 995-999.

van Wijngaarden E, Winters PC, Cory-Slechta DA. 2011. Blood lead levels in relation to cognitive function in older U.S. adults. Neurotoxicology 32: 110-115. doi: 10.1016/j.neuro.2010.11.002. Epub 2010 Nov 17. 
Vermeulen J, Neyens JC, van RE, Spreeuwenberg MD, de Witte LP. 2011. Predicting ADL disability in community-dwelling elderly people using physical frailty indicators: a systematic review. BMC Geriatr 11: 33. doi: 10.1186/1471-2318-11-33.

Wilhelm-Leen ER, Hall YN, Tamura K, Chertow GM. 2009. Frailty and chronic kidney disease: the Third National Health and Nutrition Evaluation Survey. Am J Med 122: 664-671. doi: 10.1016/j.amjmed.2009.01.026.

Wu EW, Schaumberg DA, Park SK. 2014. Environmental cadmium and lead exposures and age-related macular degeneration in U.S. adults: The National Health and Nutrition Examination Survey 2005 to 2008. Environ Res 133C: 178-184. doi:

10.1016/j.envres.2014.05.023.

Wu IC, Shiesh SC, Kuo PH, Lin XZ. 2009. High oxidative stress is correlated with frailty in elderly chinese. J Am Geriatr Soc 57: 1666-1671. doi: 10.1111/j.15325415.2009.02392.x. 


\section{TABLES}

Table 1: Blood Lead and Urine Cadmium in participants aged 60 years and older: NHANES III, 1988-1994.

\begin{tabular}{|c|c|c|c|c|c|c|c|c|}
\hline \multirow[t]{3}{*}{ Variables } & \multicolumn{4}{|c|}{ Blood lead levels $\mu \mathrm{g} / \mathrm{dl}(\mathrm{N}=5272)$} & \multicolumn{4}{|c|}{ Urine cadmium $\mu \mathrm{g} / \mathrm{L}(\mathrm{N}=4887)$} \\
\hline & & $\leq 2.9$ & \multirow{2}{*}{ 3.0-4.9 } & \multirow[t]{2}{*}{$\geq 5.0$} & \multicolumn{3}{|c|}{$\begin{array}{lll}\leq 0.41 & 0.42-0.91 \\
\end{array}$} & \multirow[t]{2}{*}{$\geq 0.92$} \\
\hline & & Weighted \% & & & $\mathrm{n}$ & \multicolumn{2}{|c|}{ Weighted \% } & \\
\hline Male gender & 2564 & 29.4 & 41.3 & 60.8 & 2418 & 58.4 & 54.4 & 54.2 \\
\hline Age, years & & & & & & & & \\
\hline $60-66$ & 1612 & 37.8 & 37.5 & 33.1 & 1595 & 35.0 & 36.5 & 42.9 \\
\hline $67-73$ & 1485 & 32.8 & 30.0 & 32.4 & 1427 & 34.2 & 32.6 & 30.0 \\
\hline$\geq 74$ & 2175 & 29.4 & 32.5 & 34.5 & 1865 & 30.8 & 30.9 & 27.1 \\
\hline \multicolumn{9}{|l|}{ Ethnicity } \\
\hline Non-Hispanic White & 3145 & 87.0 & 87.1 & 81.9 & 2831 & 85.9 & 84.9 & 83.2 \\
\hline Non-Hispanic Black & 978 & 5.3 & 6.7 & 11.4 & 961 & 6.5 & 8.2 & 9.6 \\
\hline Mexican-American & 1002 & 2.7 & 2.1 & 2.0 & 950 & 2.5 & 2.1 & 2.4 \\
\hline Other & 147 & 5.0 & 4.1 & 4.7 & 145 & 5.1 & 4.8 & 4.8 \\
\hline \multicolumn{9}{|l|}{ Education } \\
\hline$<$ High school & 2990 & 38.4 & 41.0 & 46.1 & 2722 & 35.7 & 39.8 & 45.5 \\
\hline High school & 1220 & 32.6 & 28.5 & 30.2 & 1152 & 29.4 & 30.6 & 32.5 \\
\hline$>$ High School & 1062 & 29.0 & 30.5 & 23.7 & 1013 & 34.9 & 29.6 & 22.0 \\
\hline \multicolumn{9}{|l|}{ BMI, $\mathrm{kg} / \mathrm{m}^{2}$} \\
\hline$<25$ & 1952 & 36.2 & 36.2 & 40.9 & 1761 & 37.0 & 35.1 & 39.4 \\
\hline $25-30$ & 2109 & 37.4 & 39.6 & 39.9 & 1956 & 41.4 & 37.1 & 38.9 \\
\hline$\geq 30$ & 1211 & 26.4 & 24.2 & 19.2 & 1170 & 21.6 & 27.8 & 21.7 \\
\hline \multicolumn{9}{|l|}{ Tobacco smoke } \\
\hline Never & 2476 & 58.4 & 44.4 & 29.8 & 2272 & 60.4 & 43.2 & 28.3 \\
\hline Former & 1998 & 33.0 & 40.0 & 48.2 & 1857 & 33.2 & 43.6 & 45.1 \\
\hline Current & 798 & 8.6 & 15.6 & 22.0 & 758 & 6.4 & 13.2 & 26.6 \\
\hline \multicolumn{9}{|l|}{$\begin{array}{l}\text { Number of smokers } \\
\text { at home }\end{array}$} \\
\hline 0 & 4016 & 84.2 & 78.9 & 70.0 & 3706 & 85.4 & 80.4 & 67.1 \\
\hline 1 & 948 & 12.1 & 15.7 & 21.8 & 885 & 11.9 & 15.9 & 21.9 \\
\hline$\geq 2$ & 308 & 3.7 & 5.4 & 8.2 & 296 & 2.7 & 3.8 & 11.0 \\
\hline $\begin{array}{l}\text { Osteoarticular } \\
\text { disease }\end{array}$ & 2412 & 48.3 & 46.4 & 39.5 & 2193 & 44.2 & 46.6 & 42.3 \\
\hline $\begin{array}{l}\text { Cardiovascular } \\
\text { disease }\end{array}$ & 813 & 11.0 & 12.7 & 13.4 & 693 & 9.5 & 12.3 & 11.8 \\
\hline Hypertension & 2647 & 44.4 & 45.7 & 48.0 & 2460 & 45.3 & 47.8 & 45.1 \\
\hline $\begin{array}{l}\text { Chronic respiratory } \\
\text { disease }\end{array}$ & 788 & 15.4 & 15.6 & 20.2 & 722 & 13.0 & 16.9 & 20.4 \\
\hline Diabetes & 821 & 14.8 & 13.4 & 9.4 & 747 & 12.5 & 12.2 & 11.6 \\
\hline Kidney disease & 1418 & 17.6 & 23.2 & 26.4 & 1320 & 20.8 & 23.8 & 22.5 \\
\hline Cancer & 450 & 8.4 & 9.2 & 9.4 & 400 & 8.3 & 8.4 & 9.6 \\
\hline \multicolumn{9}{|l|}{ Drug treatments } \\
\hline 0 & 1525 & 23.9 & 30.3 & 33.2 & 1449 & 30.1 & 27.8 & 31.4 \\
\hline $1-2$ & 1992 & 41.1 & 36.7 & 36.6 & 1859 & 39.7 & 39.8 & 36.6 \\
\hline$\geq 3$ & 1755 & 35.0 & 33.0 & 30.2 & 1579 & 30.2 & 32.4 & 32.0 \\
\hline
\end{tabular}


Table 2: Odds Ratios (95\% CI) for the association between blood lead levels, urine cadmium and frailty in US older adults.

\begin{tabular}{|c|c|c|c|c|c|c|c|c|c|c|}
\hline & \multicolumn{5}{|c|}{ Lead } & \multicolumn{5}{|c|}{ Cadmium } \\
\hline & $\leq 2.9 \mu \mathrm{g} / \mathrm{dl}$ & $3-4.9 \mu \mathrm{g} / \mathrm{dl}$ & $\geq 5 \mu \mathrm{g} / \mathrm{dl}$ & $\begin{array}{c}\mathrm{p}- \\
\text { trend }^{\mathrm{a}}\end{array}$ & $\begin{array}{l}\text { per intertertile } \\
\text { range }\end{array}$ & $\leq 0.41 \mu \mathrm{g} / \mathrm{l}$ & $0.42-0.91 \mu \mathrm{g} / 1$ & $\geq 0.92 \mu \mathrm{g} / \mathrm{l}$ & $\begin{array}{c}\mathrm{p}- \\
\text { trend }^{\mathrm{a}}\end{array}$ & $\begin{array}{c}\text { per intertertile } \\
\text { range }\end{array}$ \\
\hline Model 1* & 1.00 (ref) & $\begin{array}{c}1.28 \\
(0.87 ; 1.89)\end{array}$ & $\begin{array}{c}1.40 \\
(1.07 ; 1.83)\end{array}$ & 0.01 & $\begin{array}{c}1.16 \\
(1.04 ; 1.29)\end{array}$ & 1.00 (ref) & $\begin{array}{c}1.04 \\
(0.76 ; 1.43)\end{array}$ & $\begin{array}{c}1.47 \\
(1.02 ; 2.12)\end{array}$ & 0.04 & $\begin{array}{c}1.39 \\
(1.04-1.87)\end{array}$ \\
\hline Model 2* & 1.00 (ref) & $\begin{array}{c}1.33 \\
(0.88,1.99)\end{array}$ & $\begin{array}{c}1.58 \\
(1.19,2.10)\end{array}$ & $<0.01$ & $\begin{array}{c}1.16 \\
(1.04,1.29)\end{array}$ & 1.00 (ref) & $\begin{array}{c}0.98 \\
(0.70,1.38)\end{array}$ & $\begin{array}{c}1.40 \\
(0.96,2.03)\end{array}$ & 0.08 & $\begin{array}{c}1.32 \\
(1.00,1.76)\end{array}$ \\
\hline Model 3* & 1.00 (ref) & $\begin{array}{c}1.40 \\
(0.96,2.04)\end{array}$ & $\begin{array}{c}1.75 \\
(1.33,2.31)\end{array}$ & $<0.01$ & $\begin{array}{c}1.20 \\
(1.08,1.33)\end{array}$ & 1.00 (ref) & $\begin{array}{c}0.97 \\
(0.68,1.39)\end{array}$ & $\begin{array}{c}1.55 \\
(1.03,2.32)\end{array}$ & 0.04 & $\begin{array}{c}1.30 \\
(0.94,1.81)\end{array}$ \\
\hline $\begin{array}{l}\text { Sensitivity } \\
\text { analyses }\end{array}$ & & & & & & & & & & \\
\hline Model 4* & 1.00 (ref) & $\begin{array}{c}1.54 \\
(0.97,2.46)\end{array}$ & $\begin{array}{c}1.65 \\
(1.15,2.39)\end{array}$ & $<0.01$ & $\begin{array}{c}1.20 \\
(1.05,1.37)\end{array}$ & 1.00 (ref) & $\begin{array}{c}0.94 \\
(0.64,1.39)\end{array}$ & $\begin{array}{c}1.42 \\
(0.97,2.20)\end{array}$ & 0.06 & $\begin{array}{c}1.36 \\
(0.98,1.89)\end{array}$ \\
\hline Model 5 & - & - & - & - & - & 1.00 (ref) & $\begin{array}{c}0.70 \\
(0.45,1.09)\end{array}$ & $\begin{array}{c}1.67 \\
(1.05,2.66)\end{array}$ & $\mathbf{0 . 0 3}$ & $\begin{array}{c}1.14 \\
(0.95,1.36)\end{array}$ \\
\hline Model 6 & - & - & - & - & - & 1.00 (ref) & $\begin{array}{c}0.90 \\
(0.65-1.25)\end{array}$ & $\begin{array}{c}1.35 \\
(0.93-1.97)\end{array}$ & 0.12 & $\begin{array}{c}1.16 \\
(0.88-1.51)\end{array}$ \\
\hline Model 7 & 1.00 (ref) & $\begin{array}{c}1.40 \\
(0.89,2.19) \\
\end{array}$ & $\begin{array}{c}1.72 \\
(1.20,2.47)\end{array}$ & $<0.01$ & $\begin{array}{c}1.20 \\
(1.05,1.39)\end{array}$ & 1.00 (ref) & $\begin{array}{c}0.70 \\
(0.43,1.14) \\
\end{array}$ & $\begin{array}{c}1.09 \\
(0.56,2.11)\end{array}$ & 0.27 & $\begin{array}{c}1.18 \\
(0.83,1.69) \\
\end{array}$ \\
\hline
\end{tabular}

${ }^{\mathrm{a}} \mathrm{P}$-values for linear trend were calculated by assigning the median value to each tertile and treating the new variable as continuous. 
Model 1: Unadjusted.

Model 2: Adjusted for age and sex.

Model 3 adjusted for age, sex, education level (<high school, high school, >high school), ethnicity (Non-Hispanic White, Non-Hispanic Black, Mexican-American, other), body mass index, tobacco smoking (never, former, current), number of smokers at home, osteoarticular disease, cardiovascular disease, hypertension, chronic respiratory disease, diabetes, cancer, reduced glomerular filtration rate and number of drug treatments.

Model 4: Model 3 adjusted for serum cotinine concentrations. Model based on 4796 (lead) or 4596 (cadmium) participants with this information available.

\section{*For cadmium, models 1-4 further adjusted for urine creatinine concentrations}

Model 5: Model 3 dividing cadmium by urine creatinine concentrations, instead of adjusting for urine creatinine concentrations

Model 6: Model 3 neither adjusting for creatinine concentrations nor dividing by urine creatinine concentrations

Model 7: Model 3 conducted only among participants with normal glomerular filtration rate (GFR > 60mL/min/1.73 $\left.\mathrm{m}^{2}\right) ; \mathrm{N}=3854 \mathrm{for}$ lead and $\mathrm{N}=3551$ for cadmium. 


\section{FIGURE TITLES}

Figure 1: Odds Ratios (95\% Confidence Intervals) of frailty according to logtransformed blood lead and log-transformed urine cadmium based on restricted cubic splines with knots at the $10^{\text {th }}, 50^{\text {th }}$ and $90^{\text {th }}$ of their distribution.

Figure 2: Odds Ratios (95\% Confidence Intervals) of the components of frailty across tertiles of blood lead and urine cadmium in US older adults

Figure 3: Odds Ratios (95\% Confidence Intervals) of frailty per intertertile range increase in log-transformed blood lead and urine cadmium, by the main sociodemographic and lifestyle risk factors

\section{FIGURE LEGENDS}

Figure 1: Analyses for the association of lead (A) and cadmium (B) with frailty conducted in the overall population. Analyses for the association between cadmium (C) and frailty in individuals with normal kidney function $\left(\mathrm{GFR}>60 \mathrm{~mL} / \mathrm{min} / 1.73 \mathrm{~m}^{2}\right)$. The reference value is set at the 10th percentile of lead or cadmium distribution. Odds ratios are adjusted for age, sex, education level, ethnicity, body mass index, tobacco smoking, number of smokers at home, self-reported morbidity, hypertension, reduced GFR and number of drug treatments. Cadmium models are further adjusted for urine creatinine. Lines represent the Odds Ratio (thick line) and 95\% Confidence Intervals (dotted lines), and vertical bars represent the histogram of blood lead or urine cadmium distribution, as appropriate. 
Figure 2: Models are adjusted for age, sex, education level, ethnicity, body mass index, tobacco smoking, number of smokers at home, self-reported morbidity, hypertension, reduced GFR and number of drug treatments. Cadmium analyses are based on individuals with GFR $>60 \mathrm{~mL} / \mathrm{min} / 1.73 \mathrm{~m}^{2}$, with further adjustment for urine creatinine.

Figure 3: Models are adjusted for age, sex, education level, ethnicity, body mass index, tobacco smoking, number of smokers at home, self-reported morbidity, hypertension, reduced GFR and number of drug treatments. Cadmium analyses are based on individuals with GFR $>60 \mathrm{~mL} / \mathrm{min} / 1.73 \mathrm{~m} 2$, with further adjustment for urine creatinine. *Cotinine models are based on the sub-sample of participants with this information available ( $\mathrm{N}=4796$ for lead; $\mathrm{N}=4596$ for cadmium $)$. 